\title{
NOTE
}

\section{Novel Chlamydiales associated with epitheliocystis in a leopard shark Triakis semifasciata}

\author{
A. Polkinghorne ${ }^{1,5}$, H. Schmidt-Posthaus ${ }^{2}$, A. Meijer ${ }^{3}$, A. Lehner ${ }^{4}$, L. Vaughan ${ }^{1, *}$ \\ ${ }^{1}$ Institute of Veterinary Pathology, University of Zurich, Winterthurerstrasse 268, Zurich 8057, Switzerland \\ ${ }^{2}$ Centre for Fish and Wildlife Health, Institute of Animal Pathology, University of Bern, Laenggassstrasse 122, \\ Bern 3012, Switzerland \\ ${ }^{3}$ Diagnostic Laboratory for Infectious Diseases and Screening, National Institute for Public Health and the Environment, \\ PO Box 1, 3720 Bilthoven, The Netherlands \\ ${ }^{4}$ Institute for Food Safety and Hygiene, University of Zurich, Winterthurerstrasse 272, Zurich 8057, Switzerland \\ ${ }^{5}$ Present address: Institute of Health and Biomedical Innovation and School of Life Sciences, Queensland University of \\ Technology, 60 Musk Avenue, Kelvin Grove 4059, Australia
}

\begin{abstract}
The Chlamydiales is a diverse order of obligate intracellular gram-negative bacteria that are known to cause a wide range of diseases in terrestrial animals, including humans. Molecular analyses have revealed that these organisms are also associated with epitheliocystis in teleost fish species, highlighting the suspected deep evolutionary origin of members of this bacterial order. However, our knowledge of their fish host range and of the diversity of the bacteria themselves is still very limited. In this study, we provide molecular evidence for a novel member of the Order Chlamydiales in a nonteleost species, the leopard shark Triakis semifasciata. Based on phylogenetic analysis of the 16S rRNA gene, this novel organism appears to represent a unique lineage in the Order Chlamydiales despite appearing histologically similar to epitheliocystis-causing organisms in other fish species. A greater understanding of the genetic diversity of marine Chlamydiales will assist our attempts to manage and control epitheliocystis outbreaks and to understand the evolution of this unique obligate intracellular pathogen.
\end{abstract}

KEY WORDS: Epitheliocystis · Chlamydia · Leopard shark · 16S rRNA · Phylogenetic analysis · Gill pathology

Resale or republication not permitted without written consent of the publisher

\section{INTRODUCTION}

Epitheliocystis is an infectious disease of the gills and skin in many marine and freshwater fish species. Research over the last decades has provided strong ultrastructural (Paperna et al. 1981, Paperna \& Alves de Matos 1984, Turnbull 1993, Crespo et al. 1999, 2001) and antigenic evidence (Groff et al. 1996) linking the causative agents of this disease with members of the Chlamydiaceae, which are obligate intracellular bacteria which cause disease in humans and animals. More recently, molecular studies have confirmed this description, with a number of reports detecting unique Chlamydia-like organisms that are phylogenetically distinct but related to the traditional terrestrial mem- bers of this bacterial order (Draghi et al. 2004, 2007, Meijer et al. 2006, Karlsen et al. 2008). Although provisional names have been proposed for 2 of these organisms based on the salmonid host species, namely 'Candidatus Piscichlamydia salmonis' (Draghi et al. 2004) and 'Candidatus Clavochlamydia salmonicola' (Karlsen et al. 2008), we have virtually no data on the species specificity of these bacteria. Zoonotic potential can at least be inferred in one case, with a Chlamydiales with identical sequence having been discovered in conjunctival swabs from cats' eyes (von Bomhard et al. 2003) and in epitheliocystis of Arctic charr Salvelinus alpinus (Draghi et al. 2007). Further advances in our understanding of the host specificity and routes of transmission of Chlamydia-like epitheliocystis agents has 
been limited by the lack of success in isolating and cultivating these obligate intracellular bacteria from infected fish.

Epitheliocystis infections have a varying effect on the health of the infected host, ranging from no apparent effect in the mildest cases to severe proliferation of gill epithelial cells, resulting in clinical signs such as sluggishness in movement caused by respiratory insufficiency. Mortality within cultured fish populations can vary greatly, especially in juvenile fish or even larvae (Katharios et al. 2008). However, as the bacteria have yet to be cultured from epitheliocystis lesions, a direct causal proof according to Koch's postulates has not been obtained for this disease (Nowak \& LaPatra 2006). Apart from infecting cultured species of economic importance such as Atlantic salmon Salmo salar, Arctic charr Salvelinus alpinus, sea bass Dicentrarchus labrax and sea bream Sparus aurata, the disease has also been reported in ornamental species such as the leafy sea dragon Phycodurus egues (Langdon et al. 1991) (reviewed by Nowak \& LaPatra 2006).

In the present report, we provide the first molecular description of a Chlamydia-like bacterium associated with epitheliocystis in a nonteleost fish species, the leopard shark Triakis semifasciata, although morphological and histological evidence for Chlamydiales infection in epitheliocystis of white sturgeon Acipenser transmontanus in aquaculture has been reported (Groff et al. 1996). Consistent with other recent reports detecting Chlamydia-like organisms associated with epitheliocystis, the 16S rRNA sequence detected in the gill tissue represents a novel lineage among other environmental Chlamydia in the Order Chlamydiales.

\section{MATERIALS AND METHODS}

Case history. The animal described in this report was an adult female leopard shark Triakis semifasciata (3.75 kg, $100 \mathrm{~cm}$ length). The animal was kept in a quarantine tank, together with a moray eel Gymnothorax favagineus, at the Zoological Garden in Basel, Switzerland. Three months prior to the death of the animal, the shark showed multiple skin ulcerations which resolved without treatment. A few days prior to euthanasia, the animal presented deteriorating symptoms including multiple skin ulcerations, reduced breathing rate and uncoordinated swimming. Antibiotic treatment with enrofloxacin was applied unsuccessfully. Since the clinical signs of disease did not resolve, the animal was euthanized and sent to the Centre for Fish and Wildlife Health (FIWI), University of Bern, Switzerland, for further investigation.

A complete necropsy was performed. Fresh mounts of skin, gill samples and the intestinal content were collected for microscopic investigation but no evidence of the presence of parasites was found. Bacteriological examination of tissue samples of skin, liver, spleen and kidney was performed by cultivation on blood agar plates (Bio Merieux) and Bromothymol blue-lactose agar plates. Besides a mixed culture from the skin sample, cultures from the inner organs were sterile. Samples of skin, gills, heart, liver, kidney, spleen, intestine and muscle were fixed in $10 \%$ buffered formalin, trimmed and embedded in paraffin blocks and routinely processed for histology and staining with hematoxylin and eosin (H\&E).

Immunohistochemistry using Chlamydiaceae-specific antibodies. Paraffin sections were investigated for the presence of Chlamydia essentially as previously described (Soldati et al. 2004) using Chlamydiaceae family-specific mouse monoclonal antibodies (Abs) directed against the chlamydial lipopolysaccharide (cLPS; Clone ACI-P, Progen) and the EnVision kit (Dako ChemMate) according to the manufacturer's instructions. The primary antibody was prepared at a working dilution of 1:200 in antibody diluents. Intestinal tissues from gnotobiotic piglets that were experimentally infected with porcine C. suis strain S45 (Guscetti et al. 2009) were used as positive controls.

DNA extraction from formalin-fixed and paraffinembedded material. Sections $(30 \mu \mathrm{m})$ were cut from the paraffin block and stored in sterile microcentrifuge tubes. Paraffin was removed by xylene treatment, followed by repeated washing with $100 \%$ ethanol to remove residual xylene. DNA was extracted from the tissue pellet using a commercial DNA extraction kit (DNeasy tissue kit, Qiagen) according to the manufacturer's instructions.

16S rRNA Order Chlamydiales-specific PCR amplification and cloning of sequences. The presence of chlamydial DNA was detected by a pan-Chlamydiales PCR using the previously described primers 16SIGF (5'-CGG CGT GGA TGA GGC AT-3') and 16SIGR (5'-TCA GTC CCA GTG TTG GC-3') targeting the complete Chlamydiales-specific 16S rRNA signature sequence (Everett et al. 1999). Reactions were prepared by the addition of $5 \mu \mathrm{l}$ of extracted DNA to a $45 \mu \mathrm{l}$ PCR mastermix containing $1 \times$ PCR buffer, $1 \mathrm{mM}$ $\mathrm{dNTP}, 4.5 \mathrm{mM} \mathrm{MgCl} 2,0.3 \mu \mathrm{M}$ of each primer and $1 \mathrm{U}$ Fast Start Taq DNA polymerase (Roche Applied Science). The amplification reaction was performed with initial denaturation $\left(94^{\circ} \mathrm{C}, 3 \mathrm{~min}\right)$, followed by 35 cycles of denaturation at $94^{\circ} \mathrm{C}(30 \mathrm{~s})$, annealing at $54^{\circ} \mathrm{C}$ $(30 \mathrm{~s})$ and extension at $72^{\circ} \mathrm{C}(1.5 \mathrm{~min})$. The amplification reaction was completed with a final extension of $72^{\circ} \mathrm{C}$ for $10 \mathrm{~min}$. Negative controls consisting of $\mathrm{dH}_{2} \mathrm{O}$ were performed in triplicate. The presence of a resulting 298 bp PCR product was visualized by UV transillumination $(254 \mathrm{~nm})$ following separation of PCR prod- 
ucts by agarose gel electrophoresis. Reactions were repeated in triplicate and distilled water was used in negative control reactions.

Freshly amplified 16S rRNA PCR products were ligated into the pCR2.1-TOPO cloning vector (Invitrogen), and transformed into Escherichia coli TOP10 chemically competent cells (Invitrogen) according to the manufacturer's instructions. Individual clones were screened using restriction digest and the inserts sequenced with an ABI Prism 377 DNA sequencer (Applied Biosystems) or a 3100 Genetic Analyser (Applied Biosystems) using M13 forward (CGC CAG GGT TTT CCC AGT CAC GA) and M13 reverse primers (AGC GGA TAA CAA TTT CAC ACA GGA).

Molecular phylogenetic analysis. The initial identity of amplified and cloned 16S rDNA sequences was determined by BLAST-n searching (Altschul et al. 1997) of the available sequences in the GenBank database (www.ncbi.nlm.nih.gov). 16S rRNA secondary structure reconstruction and analysis was performed essentially as described previously (Meijer et al. 2006) using RNAdraw version $1.1 \mathrm{~b} 2$ and the $16 \mathrm{~S}$ rRNA secondary structure template provided by the European ribosomal RNA database (Wuyts et al. 2004) to authenticate the novel 16S rDNA sequences. After removal of the amplification primer sites, the novel 16S rDNA sequences were initially aligned with $16 \mathrm{~S}$ rRNA signature sequences from members of the Order Chlamydiales (Everett et al. 1999), including species of the traditional Chlamydiaecae family and Chlamydia-like organisms and reported 16S rRNA sequences detected in cases of epitheliocystis in other fish species, using ClustalW (Thompson et al. 1994). The final alignment, which was used for phylogenetic analysis, was manually refined taking into account the secondary structure of each sequence included using pre-aligned $16 \mathrm{~S}$ rRNA sequences and the 16S rRNA secondary structure template provided by the European ribosomal RNA database.

Phylogenetic analysis was carried out using the Tamura and Nei method (transversions and transitions included; heterogeneous patterns among lineages, gamma distributed rates among sites with a gamma parameter of 0.35 estimated using TREE-PUZZLE 5.2; Schmidt et al. 2002) to calculate a distance matrix. The phylogenetic tree was inferred by the neighbor-joining (NJ) method using MEGA software version 4.1 (Tamura et al. 2007). Maximum-likelihood (ML) analysis was carried out using the TREE-PUZZLE software version 5.2 (parameter estimation using NJ tree with the Tamura-Nei model for substitutions and gamma distributed rates among sites). Maximum-parsimony analysis was carried out using MEGA software version 4.1 via the close-neighbor-interchange method for finding the optimum tree. Chlorobium tepidum and
Piscirickettsia salmonis 16S rRNAs were used as outgroup sequences for phylogenetic tree construction. From the 3 inferred phylogenetic trees, 1 consensus tree (topology only) was constructed.

Nucleotide sequence accession number. The partial 16S rRNA gene sequence of the leopard shark epitheliocystis agent is available at GenBank under the accession number FJ001668.

\section{RESULTS}

\section{Histopathological description of leopard shark epitheliocystis}

Histological examination of the gills revealed multifocal hyperplasia of the gill epithelium. In these areas, multiple epithelial cells were necrotic showing karyopycnosis and karyorhexis. Moderate cellular infiltration was observed, mainly with eosinophilic granular cells and few macrophages. One trematode-like structure was found in the gill section, but no amoeba was observed. At multiple locations on the lamellar epithelium, intercellular edemas with interspersed inflammatory cells were present. Multiple intracellular cysts, which were often found near these lamellar lesions, were observed in enlarged epithelial cells. This enlargement appeared to be the result of the displacement of the cytoplasm and the nucleus by a large (10 to $40 \mu \mathrm{m}$ diameter), well-marginated vacuole containing what appeared to be fine, granular material (Fig. 1).

More detailed ultrastructural observations using transmission electron microscopy were attempted, but no epitheliocystis inclusions were found in the remaining limited tissue that was available for analysis.

\section{Immunohistochemical analysis of the Chlamydia-like organism associated with leopard shark epitheliocystis}

Previous reports characterizing epitheliocystis infections in different fish species have described varying cross-reactivity to antibodies that recognize immunogens expressed by the traditional members of the Chlamydiaceae (Nowak \& LaPatra 2006). To investigate this phenomenon further, we tested tissue sections immunohistologically using a monoclonal antibody (AC-I) specific for cLPS. Previous reports on the presence of this antigen in epitheliocystis cases vary (Nowak \& LaPatra 2006) and are of interest since this antigen appears to be Chlamydiaceae family specific and is not found in Chlamydia-like organisms (Corsaro \& Greub 2006). Although the Chlamydia-infected control tissues were positive, we were unable to detect any 

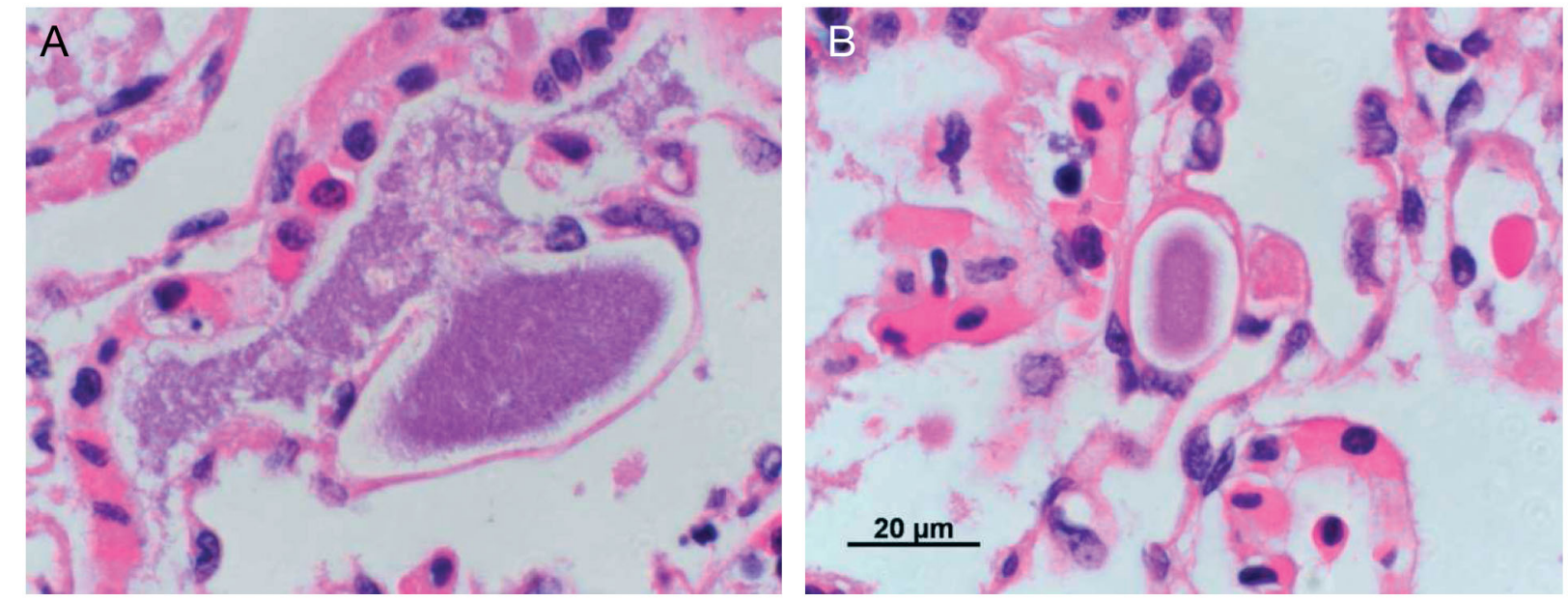

Fig. 1. Triakis semifasciata. Epitheliocystis inclusions in gill lamellae. (A) A $~ 50 \mu m$ (cross section) inclusion appears to be rupturing, releasing granular material, presumably bacteria, into the sub-epithelial space. This is an unusual feature that is rarely seen in epitheliocystis, but may imply in this case that the bacteria are thereby able to spread more widely within the host. (B) A more typical inclusion that is completely encapsulated within an epithelial cell membrane. Both (A) and (B) are reproduced at the same magnification, as indicated by the scale bar in (B)

signal with this antibody in the leopard shark sample. This suggests that the Chlamydia-like organisms detected in these tissue samples are sufficiently distant from the Chlamydiaceae so as not to carry the LPS epitope shared by members of this family (data not shown).

\section{Molecular identification of novel Chlamydia-like organisms}

DNA extracted from a section of the infected leopard shark gills was positive for chlamydial DNA following repeated testing with the Order Chlamydiales specific 16S rDNA PCR assay. Cloning and sequencing of these PCR products revealed the presence of one $294 \mathrm{bp}$ sequence that could be repeatedly amplified from the same gill sample. This sequence was designated as Uncultured Fish Chlamydiae 1 (UFC1). BLAST-n searching of the UFC1 sequence against the NCBI database revealed closest, albeit low, sequence similarity (89\%) to a $16 \mathrm{~S}$ rDNA sequence that was obtained from a case of feline ocular disease in our previous study (WB13; von Bomhard et al. 2003). A bootstrap consensus tree was constructed from trees that were derived using 3 different analyses methods to infer the phylogenetic relationship of this novel shark epitheliocystis sequence to those of the other members of the Order Chlamydiales (Fig. 2). This analysis revealed that UFC1 appears to branch separately from other members of this bacterial order and away from the traditional members of the Chlamydiaceae, forming its own lineage among other environmental Chlamydiarelated bacteria. This analysis confirms our morpho- logical observations suggesting that the bacterial agent of epitheliocystis, in the case of this leopard shark, belongs to a new and phylogenetically distinct branch of the Order Chlamydiales.

\section{DISCUSSION}

This report describes the first molecular identification of a bacterial agent associated with epitheliocystis in a nonteleost fish species, the leopard shark. Consistent with previous reports in bony fishes (Draghi et al. 2004, 2007, Meijer et al. 2006), UFC1 is genetically related to Chlamydia-like organisms, sharing $>80 \%$ sequence similarity to other members of the Order Chlamydiales (Everett et al. 1999). Although not ideal for detailed phylogenetic analysis, the short 16S rRNA signature sequence that was detected in the epitheliocystis-infected tissue is unique; however, it shared only distant similarity (89\%) with other previously reported and uncultured Chlamydia-like 16S rRNA sequences from a cat (von Bomhard et al. 2003), which in contrast were identical to sequences reported from epitheliocystis in Arctic charr (Draghi et al. 2007). The sequence that was detected in the leopard shark is clearly distinct from the latter fish epitheliocystis 16S rRNA sequences, suggesting that UFC1 is the first representative of an, as yet, unreported lineage in the Order Chlamydiales. Also, in contrast to the Arctic charr epitheliocystis case, we found no staining with a Chlamydiaceae-specific anti-LPS antibody, which further supports this conclusion.

The epitheliocystis infection was unresponsive to treatment with enrofloxacin, which would be effective 
against Chamydiaceae, but not against Chlamydialike organisms (Casson \& Greub 2006, Goy \& Greub 2009). Interestingly, these organisms are sensitive to tetracyclines. Oxytetracyclines have previously been found to be effective in treating epitheliocystis infec- tions in largemouth bass (Goodwin et al. 2005), and this strategy may be the preferred treatment for future epitheliocystis outbreaks.

We have only begun to appreciate how considerable the diversity and abundance of members of the

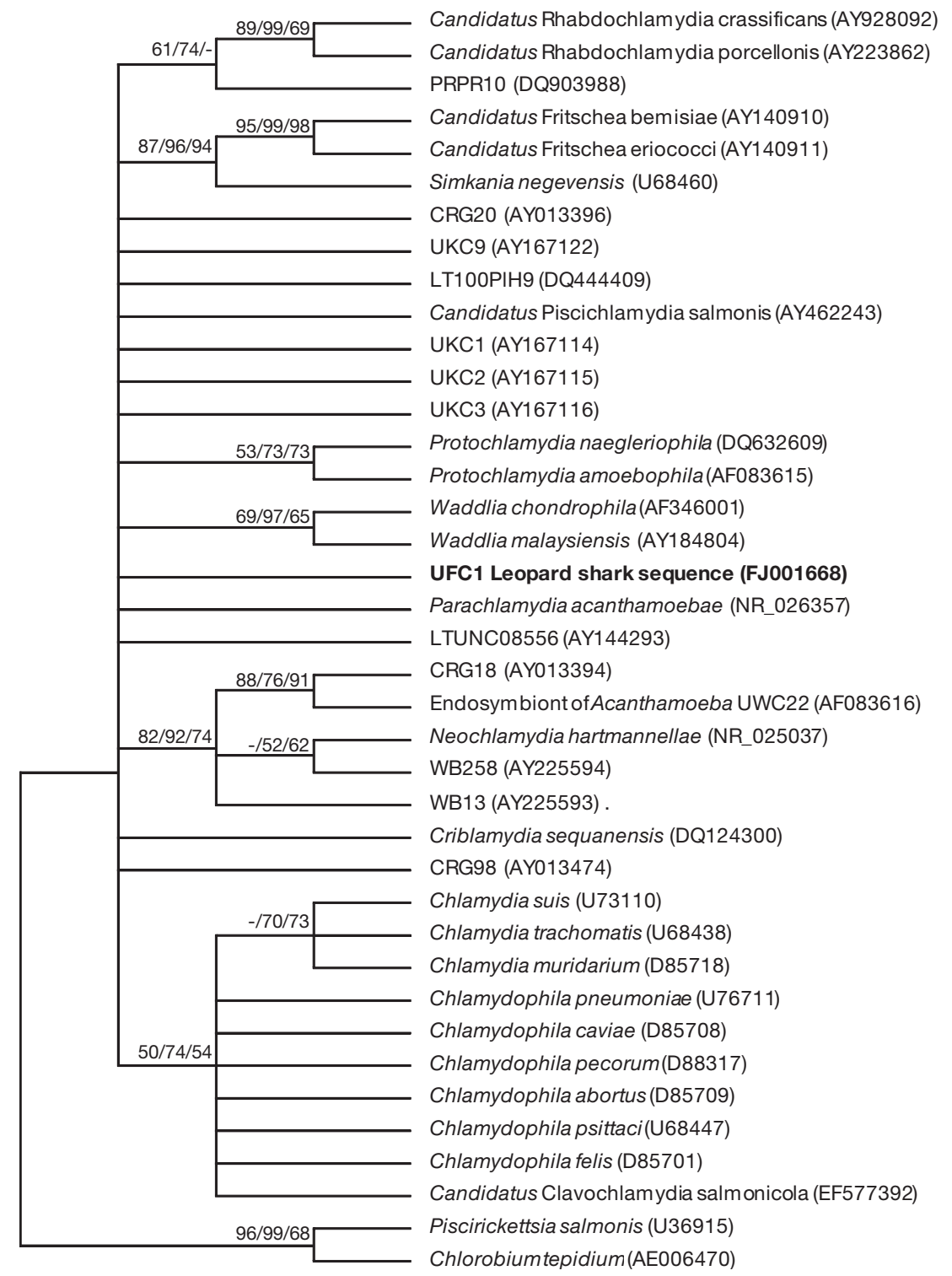

Fig. 2. Phylogenetic relationships between the novel leopard shark epitheliocystis 16S rRNA sequence (Uncultured Fish Chlamydiae 1, UFC1) and those of selected members of the Order Chlamydiales. The tree was inferred by using neighbor joining (NJ), maximum-parsimony (MP) and maximum-likelihood (ML) analysis of a 260 bp region of the 16S rRNA Chlamydiales signature sequence. The tree was rooted using the distant Piscirickettsia salmonis and Chlorobium tepidium. Numbers indicate the percentage of times each branch appeared in a tree during 10000 bootstrap samples (NJ and MP) or puzzling steps (ML) in the order (NJ/MP/ML). Multifurcations connect branches for which the relative order could not be unambiguously determined. Branches supported by a bootstrap or puzzling reliability value of $>50 \%$ in at least 2 treeing methods are shown. GenBank accession numbers are given in parentheses. Included in the phylogenetic tree are representative sequences of type strains of classified Chlamydiaceae, along with the sequences of cultured Chlamydia-like organisms isolated from diverse hosts including amoeba, invertebrates, fish, and marsupial and placental mammals (Criblamydia sequanensis, Waddlia chondrophila, W. malaysiensis, Parachlamydia acanthamoebae, Neochlamydia hartmanellae, Simkania negevensis, 'Candidatus Rhabdochlamydia porcellonis', 'Candidatus Rhabdochlamydia crassificans', Protochlamydia amoebophila, P. naegleriophila, 'Candidatus Fritschea eriococci', 'Candidatus F. bemisiae', and an endosymbiont of Acanthamoeba UWC22) 
Order Chlamydiales in the environment really is; many of these members have been isolated from rivers, lakes and water treatment plants via the amoebal co-culture method (Corsaro \& Greub 2006). This takes advantage of the ability of many Chlamydiales to utilize amoeba as hosts, simplifying their isolation from contaminating microorganisms that are not equipped to survive amoebal predation (Thomas et al. 2006, 2008, Corsaro et al. 2009). The success of this isolation method has led to the proposal that many environmental members of the Chlamydiales may use amoeba as intermediate hosts (Greub \& Raoult 2004), and could possibly pass from infected amoeba occupying the gills and epidermis directly to the fish host. Unfortunately, an alternative to isolation and identification of potential vertebrate Chlamydiales pathogens via the indirect amoebal route is to target pathogens of fish directly. For this reason, we and others (Meijer et al. 2000, 2006, Draghi et al. 2004, 2007, Nowak \& LaPatra 2006, Karlsen et al. 2008) are attempting to molecularly identify and categorize the agents of epitheliocystis. Initial investigations have identified the novel bacteria relative to their hosts, as evident in their names 'Candidatus Piscichlamydia salmonis' (Draghi et al. 2004) and 'Candidatus Clavochlamydia salmonica' (Karlsen et al. 2008), raising the question of host specificity. However, it was observed that Chlamydiales discovered in epitheliocystis of Arctic charr from Virginia (USA) (Draghi et al. 2007) were partly identical to Chlamydiales identified in conjunctivitis infections of cats in Zurich (von Bomhard et al. 2003); this raised the very real possibility that these Chlamydiales are zoonotic pathogens that are widely spread geographically and are able to cause disease over a broad spectrum of vertebrate hosts.

We now extend these observations to provide the first molecular evidence for Chlamydiales infection of a nonteleost fish. This result should help stimulate others to investigate the molecular basis of epitheliocystis infections and encourage efforts to isolate these organisms directly from their fish hosts, the success of which is still proving to be elusive. This would be an important step as only when we have successfully isolated and cultivated Chlamydiales bacteria from fish with epitheliocystis will we be able to establish experimental fish models to test whether the bacteria can directly infect their hosts or whether an intermediate host, e.g. an amoeba, is necessary.

Acknowledgements. A.P. was supported by SBF Project C07.0125 awarded to L.V. as part of COST Action 867: Fish Welfare. We thank T. Jermann and C. Wenker of the Zoological Garden of Basel, Switzerland, for providing the leopard shark case material and information on history, clinic and treatment.

\section{LITERATURE CITED}

Altschul SF, Madden TL, Schäffer AA, Zhang J, Zhang Z, Miller W, Lipman DJ (1997) Gapped BLAST and PSIBLAST: a new generation of protein database search programs. Nucleic Acids Res 25:3389-3402

> Casson N, Greub G (2006) Resistance of different Chlamydialike organisms to quinolones and mutations in the quinolone resistance-determining region of the DNA gyrase A- and topoisomerase-encoding genes. Int J Antimicrob Agents 27:541-544

Corsaro D, Greub G (2006) Pathogenic potential of novel chlamydiae and diagnostic approaches to infections due to these obligate intracellular bacteria. Clin Microbiol Rev 19:283-297

Corsaro D, Feroldi V, Saucedo G, Ribas F, Loret JF, Greub G (2009) Novel Chlamydiales strains isolated from a water treatment plant. Environ Microbiol 11:188-200

Crespo S, Zarza C, Padrós F, Marín de Mateo M (1999) Epitheliocystis agents in sea bream Sparus aurata: morphological evidence for two distinct chlamydia-like developmental cycles. Dis Aquat Org 37:61-72

> Crespo S, Zarza C, Padrós F (2001) Epitheliocystis hyperinfection in sea bass, Dicentrarchus labrax (L.): light and electron microscope observations. J Fish Dis 24:557-560

Draghi A, Popov VL, Kahl MM, Stanton JB and others (2004) Characterisation of 'Candidatus Piscichlamydia salmonis' (Order Chlamydiales), a chlamydia-like bacterium associated with epitheliocystis in farmed Atlantic salmon (Salmo salar). J Clin Microbiol 42:5286-5297

> Draghi II A, Bebak J, Popov VL, Noble AC and others (2007) Characterization of a Neochlamydia-like bacterium associated with epitheliocystis in cultured Arctic charr Salvelinus alpinus. Dis Aquat Org 76:27-38

Everett KD, Bush RM, Andersen AA (1999) Emended description of the order Chlamydiales, proposal of Parachlamydiaceae fam. nov. and Simkaniaceae fam. nov., each containing one monotypic genus, revised taxonomy of the family Chlamydiaceae, including a new genus and five new species, and standards for the identification of organisms. Int J Syst Bacteriol 49:415-440

Goodwin AE, Park E, Nowak BF (2005) Successful treatment of largemouth bass, Micropterus salmoides (L.), with epitheliocystis hyperinfection. J Fish Dis 28:623-625

Goy G, Greub G (2009) Antibiotic susceptibility of Waddlia chondrophila in Acanthamoeba castellanii amoebae. Int J Antimicrob Agents 53:2663-2666

> Greub G, Raoult D (2004) Microorganisms resistant to freeliving amoebae. Clin Microbiol Rev 17:413-433

> Groff JM, LaPatra SE, Munn RJ, Anderson ML, Osburn BI (1996) Epitheliocystis infection in cultured white sturgeon (Acipenser transmontanus): antigenic and ultrastructural similarities of the causative agent to the chlamydiae. J Vet Diagn Invest 8:172-180

Guscetti F, Schiller I, Sydler T, Heinen E, Pospischil A (2009) Experimental enteric infection of gnotobiotic piglets with Chlamydia suis strain S45. Vet Microbiol 135:157-168

Karlsen M, Nylund A, Watanabe K, Helvik JV, Nylund S, Plarre H (2008) Characterization of 'Candidatus Clavochlamydia salmonicola': an intracellular bacterium infecting salmonid fish. Environ Microbiol 10:208-218

Katharios P, Papadaki M, Papandroulakis N, Divanach P (2008) Severe mortality in mesocosm-reared sharpsnout sea bream Diplodus puntazzo larvae due to epitheliocystis infection. Dis Aquat Org 82:55-60

> Langdon JS, Elliott K, MacKay B (1991) Epitheliocystis in the leafy sea-dragon. Aust Vet J 68:244 
Meijer A, Roholl PJM, Gielis-Proper SK, Meulenberg YF, Ossewaarde JM (2000) Chlamydia pneumoniae in vitro and in vivo: a critical evaluation of in situ detection methods. J Clin Pathol 53:904-910

Meijer A, Roholl PJM, Ossewaarde JM, Jones B, Nowak B (2006) Molecular evidence for association of Chlamydiales bacteria with epitheliocystis in leafy seadragon (Phycodurus eques), silver perch (Bidyanus bidyanus), and barramundi (Lates calcarifer). Appl Environ Microbiol 72: $284-290$

Nowak BF, LaPatra SE (2006) Epitheliocystis in fish. J Fish Dis 29:573-588

Paperna I, Alves de Matos AP (1984) The developmental cycle of epitheliocystis in carp, Cyprinus carpio L. J Fish Dis 7:137-147

Paperna I, Sabnai I, Zachary A (1981) Ultrastructural studies in piscine epitheliocystis: evidence for pleomorphic developmental cycle. J Fish Dis 4:459-472

Schmidt HA, Strimmer K, Vingron M, von Haeseler A (2002) TREE-PUZZLE: maximum likelihood phylogenetic analysis using quartets and parallel computing. Bioinformatics 18:502-504

Soldati G, Lu ZH, Vaughan L, Polkinghorne A, Zimmermann DR, Huder JB, Pospischil A (2004) Detection of Mycobacteria and Chlamydiae in granulomatous inflammation of

Editorial responsibility: Catherine Collins,

Aberdeen, UK reptiles: a retrospective study. Vet Pathol 41:388-397

Tamura K, Dudley J, Nei M, Kumar S (2007) MEGA4: Molecular Evolutionary Genetics Analysis (MEGA) software version 4.0. Mol Biol Evol 24:1596-1599

Thomas V, Casson N, Greub G (2006) Criblamydia sequanensis, a new intracellular Chlamydiales isolated from Seine river water using amoebal co-culture. Environ Microbiol 8:2125-2135

Thomas V, Loret JF, Jousset M, Greub G (2008) Biodiversity of amoebae and amoebae-resistant bacteria in a drinking water treatment plant. Environ Microbiol 10:2728-2745

- Thompson JD, Higgins DG, Gibson J (1994) CLUSTAL W: improving the sensitivity of progressive multiple sequence alignment through sequence weighting, position-specific gap penalties and weight matrix choice. Nucleic Acids Res 22:4673-4680

Turnbull JF (1993) Epitheliocystis and salmonid rickettsial septicaemia. In: Inglis V, Roberts RJ, Bromage NR (eds) Bacterial diseases of fish. Blackwell Scientific, Oxford, p 237-254

von Bomhard W, Polkinghorne A, Lu ZH, Vaughan L and others (2003) Detection of novel Chlamydiae in cats with ocular disease. Am J Vet Res 64:1421-1428

Wuyts J, Perriere G, Van de Peer Y (2004) The European ribosomal RNA database. Nucleic Acids Res 32:D101-D103

Submitted: December 6, 2009; Accepted: June 16, 2010 Proofs received from author(s): July 9, 2010 